Published in final edited form as:

J Fam Issues. 2011 February 1; 32(2): 209-236. doi:10.1177/0192513X10377066.

\title{
Adolescent Precursors of Early Union Formation among Asian Americans and Whites
}

\author{
Yen-hsin Alice Cheng ${ }^{*}$ and Nancy S. Landale ${ }^{* *}$ \\ "Max Planck Institute for Demographic Research 18057 Rostock, Germany \\ ${ }^{*}$ Department of Sociology Pennsylvania State University University Park PA 16802
}

\section{Abstract}

Using a framework that emphasizes independent vs. interdependent self-construals, this study investigates the relatively low rates of early marriage and cohabitation among Asian Americans compared to Whites. Data from Waves 1 and 3 of Add Health are used to test five hypotheses that focus on family value socialization and other precursors measured in adolescence. Analyses of early marriage indicate that the Asian-White difference is driven primarily by differences in adolescent sexual and romantic relationship experiences, and several measures of family values play a stronger role among Asian Americans than Whites. Asian-White differences in cohabitation persist net of SES and other adolescent precursors, but differences are attenuated when parental value socialization, intimate relationship experiences, and educational investments are controlled. These results are interpreted within a culturally sensitive conceptual framework that emphasizes interdependent construals of the self among Asian Americans.

\section{Keywords}

marriage; cohabitation; Asian Americans; culture

\begin{abstract}
Despite burgeoning interest in differences in union formation patterns among racial/ethnic minority groups, few studies of marriage or cohabitation in the United States have incorporated Asian Americans. Data from the 2000 Census show that the median ages at first marriage for Asian American men and women are higher than those for White Americans: 29 versus 26 for men and 26 versus 24 for women ${ }^{1}$. When compared to other racial/ethnic groups, Asian men have the highest median age at first marriage, whereas Asian women have the second highest (only lower than Black women). Nonetheless, most Asian Americans eventually marry 2 . The 2006 American Community Survey indicates that among all individuals ages 15 and above, $30 \%$ of Asian Americans had never married. This figure is only slightly higher than that for Whites (27\%), who have the lowest percentage never married among all racial/ethnic groups.
\end{abstract}

Several exceptions to the scarcity of literature on union formation among young Asian Americans are studies by East (1998), Glick, Ruf, White, and Goldscheider (2006), and Plotnick (2007). East and Plotnick look at adolescents' expectations for marriage. Glick et al. study the marital behaviors of Asian young adults, with a specific focus on the effect of

\footnotetext{
Direct correspondence to: Yen-hsin Alice Cheng, Max Planck Institute for Demographic Research, Konrad-Zuse-Str. 1, 18057 Rostock, Germany. Tel: 49-381-2081245. Fax: 49-381-2081545. cheng@ demogr.mpg.de.

${ }^{1}$ Simmons, T. \& Dye, J. L. (2004) What has Happened to Median Age at First Marriage Data? URL: http://www.census.gov/acs/www/Downloads/MedAge_revised_final.pptS

${ }^{2}$ U.S. Census Bureau (2007) Table S1201. Marital Status of the 2006 American Community Survey. URL:

http://factfinder.census.gov/servlet/ACSSAFFPeople?_submenuId=people_11\&_sse=on
} 
educational engagement in adolescence. However, there are good reasons to believe that the delay in union formation among Asian young adults is not due only to education, given the cultural values regarding sex and intimate relationships emphasized in Asian families (Espiritu, 2001; Staples \& Mirande, 1980) and the relatively low engagement of Asians in romantic relationships in adolescence (Carver, Joyner, \& Udry, 2003). Thus, it is important for family scholars to understand more about the processes that lead to prolonged transitions to adulthood among Asian youth.

Recent studies of union formation have emphasized continuities between adolescence and adulthood (Crissey, 2005; Manning, Longmore, \& Giordano, 2007; Plotnick, 2007; Raley, Crissey, \& Muller, 2007). Increasingly, scholars argue that the family values and attitudes toward sex and intimate relationships acquired in the teenage years foreshadow union formation (i.e., cohabitation and marriage) expectations and behaviors in the early adult years. Indeed, several studies have shown that patterns of union formation in young adulthood can be predicted from attitudes and experiences in adolescence. For example, romantic relationship experiences at the end of high school increase the likelihood of marriage, whereas nonromantic sexual experiences predict later cohabitation (Raley et al., 2007). Furthermore, racial differences in adolescent values and attitudes toward sexual behaviors and union formation have been reported. For example, when asked about desired ages at marriage and first birth, Hispanic and Black girls desire faster transitions than White or Southeast Asian girls (East, 1998).

This article seeks to contribute to the literature on race/ethnicity and union formation in several ways. First, we focus on Asian Americans, a group that is understudied despite the fact that they are the fastest growing racial minority group in the United States. According to the U.S. Census Bureau, the Asian American population is projected to grow from $1 \%$ of the U.S. population in 1970 to $10 \%$ in 2050 (Martin \& Midgley, 2003). Comparisons are made between Asian and White Americans because of their similar socioeconomic profiles and yet quite different rates of union formation. Second, we develop a conceptual framework to understand Asian-White differences in values and behavior, drawing on a theory that emphasizes two distinct perspectives on self-construals (independent versus interdependent). Attention to how values are internalized in culturally diverse families provides insight into the mechanisms underlying behavioral differences. Third, we address multiple understudied research issues by: (1) focusing on both marriage and cohabitation among Asian Americans; (2) looking at actual occurrences of marriage and cohabitation, rather than expectations about unions; (3) simultaneously examining the influences of family values, adolescents' own sexual and relationship values, adolescents' sexual and relationship experiences, and educational investments on the transition to first union; and (4) utilizing a nationally representative sample of a recent cohort of White and Asian youth.

\section{Conceptual Framework}

\section{Race and Union Formation}

Over the past few decades, the mean age at first marriage and the percentage of nevermarried individuals at most ages have been on the rise (Casper \& Bianchi, 2002). Cohabitation has become prevalent, whether or not it is followed by marriage. Differences in patterns of union formation have been reported repeatedly for Whites, Blacks, and Hispanics (Bumpass \& Lu, 2000; Manning \& Smock, 1995; Schoen \& Cheng, 2006), but because of the limited attention to Asian Americans, the portrait of their union formation behavior is less complete.

Glick et al. (2006), using the National Education Longitudinal Study (NELS), reported a lower likelihood of entry into marriage for Asian youth when compared to Whites. 
However, the difference between Asians and Whites was non-significant after family socioeconomic status and generation status were considered. Findings from East's (1998) study indicate that when family characteristics and socioeconomic background are controlled, Southeast Asian girls prefer later and more gradual transitions to sexual, marital, and birth events than Hispanic and Black girls. Finally, Plotnick (2007) found that Asian American adolescents have significantly higher expected and desired age of marriage than White adolescents. All of these studies accentuate the need to further explore the factors involved in differences in the timing of union formation between White and Asian American young adults.

\section{Perspectives on Self-Construal as a Way to Understand Family Influences}

The term "self-construal" refers to the awareness and conception of oneself in relation to others, especially the extent to which one sees how he/she is separated from or connected with others (Markus \& Kitayama, 1991). The seminal work of Markus and Kitayama (1991) offers an explanation for the association between different construals of the self and the process of family value socialization among Western and Eastern/Asian cultures. They point out two distinct types of self-construals: independent versus interdependent. The independent view of Western culture sees the self as "deriving from a belief in the wholeness and uniqueness of each person's configuration of internal attributes" (p.226). In contrast, the interdependent notion of the self in Asian culture "entails seeing oneself as part of an encompassing social relationship and recognizing that one's behavior is determined, contingent on, and, to a large extent organized by what the actor perceives to be the thoughts, feelings, and actions of others in the relationship" (p. 227). This interdependent view of the self is not only present in East Asian countries where Confucian values prevail, but can also be found in the Philippines, India, or even Hispanic and African cultures. The concept of an interdependent self-construal resembles aspects of Confucian familism that stress affective and cognitive identification with one's family and understanding one's responsibilities and obligations toward his/her family (Cheng, 1944). These two distinct views of the self have implications for family socialization because they motivate individuals' actions and behaviors in dissimilar ways. A person with an independent selfconstrual is motivated to do things that realize his or her own desires or needs, while a person with an interdependent self-construal is motivated toward actions that promote connection to and meet the expectations of significant others.

Using this framework, one would expect family values to play a role in Asian-White differences in family formation. Asian parents may hold more conservative values regarding sexuality and early union formation than White parents. Further, family values may have a stronger influence on Asian American youth, suggesting an interaction between race and family values in models of union formation.

\section{Family Value Socialization and Adolescents' Values}

Asian culture places strong constraints on young people's premarital sexual behaviors and cohabitation (Chan, 1994; Espiritu, 2001; Staples \& Mirande, 1980). This is true in countries influenced by the Confucian culture as well as other countries like the Philippines, even though recent trends indicate a rise in premarital sex and cohabitation in such settings (Jones, 2005, 2007; Williams, Kabamalan, \& Ogena, 2007). First- and second-generation Asian American adolescents remain under the strong influence of the Asian value system because of their exposure to immigrant parents. For example, Espiritu's (2001) qualitative study of first- and second-generation Filipino daughters and their parents reveals strong parental disapproval of sex along with strict parental control of daughters' sexuality and dating choices. This causes conflicting emotions in daughters who want to adapt to the U.S. culture and to stay true to their ethnic identity. 
Another source of family values is religion. Offspring of more religious parents are more likely to internalize conservative family values than offspring of less religious parents (Regnerus, 2003). They may therefore perceive more negative social consequences of early sexual and dating activities, which may deter actual involvement in these activities. Lower involvement in sex and dating decreases the likelihood of cohabitation and marriage in early adulthood (Crissey, 2005; Manning et al., 2007; Meier \& Allen, 2007; Raley et al., 2007). At the same time, prior research shows that religiosity has a positive effect on the perceived likelihood of marriage (Crissey, 2005; Manning et al., 2007) and a negative effect on cohabitation (Manning et al., 2007; Thornton, Axinn, \& Hill, 1992; Williams et al., 2007).

Parental attitudes about dating and sex are also intertwined with parents' aspirations for their children. Asian families place great emphasis on making sure the young excel in school and advance to higher education (Hirschman \& Wong, 1986; Nakanishi \& Nishida, 1995), and Asian American youth invest considerable time and energy pursuing educational goals that fulfill the expectations of family members (Asakawa \& Csikszentmihalyi, 2000), often their parents. As a consequence, they are likely to refrain from seeking sexual or romantic relationships that are considered secondary or inappropriate in adolescence (Espiritu, 2001).

We expect parental values to partially explain Asian-White differences in union formation (Hypothesis 1). Parents of Asian American adolescents are likely to place greater emphasis on postsecondary education, to be more religious, and to be more disapproving of adolescent sexual activity than are parents of White adolescents. We also expect differences between Asian and White adolescents in their attitudes about sex and family formation, and anticipate that these differences will account partially for differences in union formation behavior (Hypothesis 2). If Asian parents hold values that are different from those of White parents or if internalization of family values is deeper among Asians, Asian adolescents should differ from Whites in their perceived social consequences of sex, their motivation to have sex, and their views on premarital pregnancy. These discrepancies may further translate into different union patterns in young adulthood. In addition, given that selfconstrual theory maintains that Asians adhere more strongly to family values than Whites, we expect parents' and adolescents' values to be related more strongly to union formation among Asian Americans than among Whites (Hypothesis 3).

\section{Sexual and Relationship Experiences}

Recent studies have investigated the links between both romantic relationships and union formation expectations in adolescence and union formation behaviors in young adulthood. Crissey (2005) finds that adolescents who are involved in serious relationships are more likely than others to think that they will get married by age 25. Raley and colleagues (2007) report similar findings, except the outcomes in their study are actual marriage and cohabitation. They show that adolescents who have romantic relationships by the end of high school are more likely to be married and to cohabit in early adulthood than those who do not. In addition, nonromantic sexual relationships in adolescence elevate the risk of cohabitation, but not marriage. Meier and Allen (2007) show that adolescents who have a history of either "progression to a steady relationship" or "remaining in a stable steady relationship" are significantly more likely to get married. Further, those who never had any relationship by early adulthood are much less likely to cohabit. Similarly, Manning et al. (2007) find that adolescents who have never dated are less likely to expect to cohabit before marriage than adolescents who are currently dating. They also show that sexual activity in adolescence increases the likelihood of expecting the "cohabitation then marriage" pathway instead of the "direct marriage" pathway (Manning et al., 2007). Together, these studies make clear that adolescent relationship experiences are critical precursors of union formation behavior in young adulthood. Thus, it is hypothesized that Asian adolescents' limited experiences in sexual and romantic relationships (Carver et al., 2003; Chris \& Hahm, 
2006) will partially explain their relatively low rates of forming marital and cohabitating unions (Hypothesis 4).

\section{Educational Investments}

The relationship between schooling and union formation has been tested extensively (Glick et al., 2006; Hango \& Le Bourdais, 2007; Mare \& Winship, 1991; Thornton et al., 1995). Both school enrollment and greater investment in education are associated with later union formation, especially marriage. Although schooling may have a weaker effect on minority youths for whom socioeconomic advancement is blocked structurally (Edin \& Kefalas, 2005; Hogan \& Kitagawa, 1985), this is generally not the case for Asian Americans. Asian Americans have relatively high rates of attending elite universities, getting professional or managerial jobs, and making high income when compared with other minority groups (Barringer, Takeuchi, \& Xenos, 1995; Hirschman \& Wong, 1986). Asians' high investments in education should delay their union formation. In fact, Glick et al.'s (2006) study demonstrated that Asian teens with high educational engagement have a very low predicted probability of marriage.

East's (1998) study further highlights the links between race/ethnicity, education, and union formation. East argues that despite the similar socioeconomic profiles of Southeast Asian and Black girls, the former have higher educational and job aspirations than the latter, and this lowers their desire for early sexual and marital events. Family culture plays a key role in this difference. Asian parents' expectations are also high in comparison to those of White parents. It is thus hypothesized that educational investments contribute to the relatively low rates of early union formation of Asian Americans compared to White Americans (Hypothesis 5).

To sum up, to unravel the processes underlying Asian-White differences in the formation of cohabiting and marital unions, we investigate five hypotheses: (H1) Parental values will partially explain Asian-White differences in union formation; (H2) Differences between Asian and White adolescents in their attitudes about sex and family formation will account partially for differences in union formation behavior; (H3) Parents' and adolescents' values will be related more strongly to union formation among Asian Americans than among Whites; (H4) Asian adolescents' limited experiences in sexual and romantic relationships will partially explain their relatively low rates of forming marital and cohabitating unions; and (H5) Educational investments contribute to the relatively low rates of early union formation of Asian Americans compared to White Americans. Throughout our analyses, we control for socioeconomic background because of its well-established role in union formation. It is important to bear in mind that our analysis focuses on early union formation - that is, union formation before age 25 .

\section{Research Design \\ Data}

This paper employs data from Waves 1 and 3 of Add Health, a longitudinal study that began with a national sample of adolescents in grades 7-12 in 1994-1995. Students were selected from a sampling frame of 26,666 U.S. high schools, including public, private, and parochial schools. These schools were grouped into strata based on enrollment size, school type, region, urbanity, and percent White students. Schools were selected using systematic sampling methods and implicit stratification. Students within each selected school were chosen with a known probability sampling method. Minority groups including Asians, Cubans, Puerto Ricans and African Americans from well-educated families were oversampled. Post-stratification adjustments were made so that the sum of school weights would equal the number of schools in each region (Harris et al., 2003). 
The data were collected mainly through in-home interviews, with extra parent questionnaires in Wave 1. The first wave of Add Health data was collected between September 1994 and December 1995. The Wave 2 in-home interviews were conducted between April 1996 and August 1996. Finally, the Wave 3 in-home interviews were conducted between 2001 and 2002.

\section{Sample}

The sample selected for the current study is individuals who participated in the Wave 1 and Wave 3 Add Health in-home interviews ( $\mathrm{n}=11,621)$. We excluded 793 individuals because they lacked the longitudinal sampling weight for analyses using Wave 1 and Wave 3, resulting in 10,828 respondents. Respondents who were between the ages of 16 and 18 at Wave 1 and who were of White or Asian race were further selected. We restrict our analytic sample to individuals ages 16 to 18 at Wave 1 because they were old enough for a sufficient number of marriages and cohabitations to have occurred by Wave 3 (when they were ages 22 to 25). Respondents who were younger were much less likely to have formed a union, especially a marriage. Individuals who were older than 18 and still enrolled in $12^{\text {th }}$ grade at Wave 1 are most likely those who experienced grade retention. They may possess common unobserved characteristics that could introduce biases into the analyses. Second, late adolescence is a time when many adolescents have experienced some level of involvement in intimate relationships, which facilitates investigation of the association between adolescent sexual and romantic relationships and young adult union formation.

There were 4,528 adolescents who met these selection criteria (3,857 Whites and 671 Asians). Although there were too few Asians to conduct our analyses separately by nationalorigin group, we recognize that union formation patterns vary across Asian subgroups. Thus, we provide descriptive information on cohabitation and marriage for Asian subgroups. Using the seven response categories for the question "what is your Asian background?" at Wave 1, we separate the Asian sample into East Asians (Chinese, Japanese, Koreans), Filipinos, and other Asians (Asian Indians, Vietnamese, other Asian ethnic groups). There were 171 East Asians, 346 Filipinos, and 154 other Asians.

Our multivariate analysis is based on a person-year file that includes observations for each year between Wave 1 and the specific union transition (either entry into a cohabitation or a marriage) being analyzed. If a respondent never experienced any union, the last observation is the year in which the Wave 3 interview was conducted. Some respondents were excluded because they experienced either a marriage or a cohabitation prior to the Wave 1 interview; these respondents were not at risk of a first union transition between Wave 1 and Wave 3 . Twenty seven adolescents had married and 107 adolescents had cohabited by Wave 1 . These individuals were left-censored from the relevant statistical analyses. The multivariate analyses of first marriage and first cohabitation are based on 4501 and 4421 respondents, respectively. These analyses are based on different numbers of individuals because of differences in the number of adolescents experiencing each event before Wave 1.

\section{Variables and Measures}

Outcome Variables-Respondents were asked to report the month and year of their first marriage and their first cohabitation in Wave 3. From these dates, century months were calculated for entry into marriage and cohabitation. When both the month and the year were missing, the case was deleted from the analysis. When the month was unknown and the year was available, the case was retained and we assumed that the event occurred in the middle of the year (i.e., in June). The outcome variables were coded ' 0 ' until the year in which the event of interest took place. To determine the year of a particular union event, the century 
month of the event was compared to the century months in which the person year started and ended. If the event fell within the person year, the event variable was coded ' 1. '

Sociodemographic Control Variables-The sociodemographic characteristics included in this study are age, gender, maternal education, family income, and family structure at Wave 1. Prior studies document that the socioeconomic status of the origin family affects the likelihood of marriage and cohabitation. For example, Schoen, Landale, Daniels, and Cheng (2009) show that among White and Black women, higher maternal education is associated with fewer transitions to cohabitation and marriage in young adulthood. It is also well documented that children who experienced parental divorce or lived in a stepfamily are more likely to form marital or cohabiting unions early than those from intact two-biological-parent families (Michael \& Tuma, 1985). Family structure is a four-category variable: two biological parents, stepfamily, single parent family, and other family. ${ }^{3}$

Predictors-Family socialization and adolescent attitudes are measured with two sets of variables from Wave 1 . The variables in the first set, which pertain to family socialization are: parental college aspirations for the adolescent, parental religiosity, and whether the parent disapproves of sex for the adolescent now. These variables are based on parental reports. Parents' aspirations for their adolescent's education are measured using the question "how disappointed would you be if [respondent] did not graduate from college? Higher disappointment is coded as higher aspirations for the youth to attend and finish college. Parental religiosity is measure by adding three items: (1) How often have you gone to religious services in the past year? (2) How important is religion to you? (3) How often do you pray? Higher scores indicate stronger religiosity (Cronbach's Alpha=0.74). Parental disapproval of sex is measured by the question "You disapprove of [respondent] having sexual intercourse at this time in his/her life," with response values ranging from 1 to 5. Higher values indicate stronger parental disapproval of sex.

The second set of variables relates to adolescents' own values and attitudes, including the perceived social consequences of sex, motivation to have sex, and whether he/she would consider having children as an unmarried person. Perceived social consequences of sex are measured with a composite variable based on three items (Cronbach's Alpha=0.69): (1) If you had sexual intercourse, your partner would lose respect for you; (2) If you had sexual intercourse, afterward, you would feel guilty; (3) If you had sexual intercourse, it would upset your mother. Higher values indicate stronger perceived social consequences of sex. The scale for motivation to have sex (Cronbach's Alpha=0.77) was created by adding the following five items: (1) If you had sexual intercourse, your friends would respect you more; (2) If you had sexual intercourse, it would give you a great deal of physical pleasure; (3) If you had sexual intercourse, it would relax you; (4) If you had sexual intercourse, it would make you more attractive to women (or men); (5) If you had sexual intercourse, you would feel less lonely. Higher values indicate stonger motivations to have sex. Finally, "consider having kids as an unmarried person" is a dichotomous variable. This variable is constructed using the question "Regardless of whether you have ever had a child, would you consider having a child in the future as an unmarried person?"

Sexual and romantic relationship experiences are measured with three dichotomous variables constructed from Wave 1 data: ever had a romantic relationship, ever had a sexual experience, and ever had sex with a non-romantic partner. Three questions form the basis for

\footnotetext{
${ }^{3}$ It is important to note that the Asian sample is largely made up of first- and second-generation individuals (90\% versus $5 \%$ for Whites), whereas the majority of Whites are third or higher generation (95\% versus $10 \%$ for Asians). Because generation status overlaps so fully with race (see Table 1), it was not possible to include it as a predictor.
} 
these variables: (1) In the last 18 months, have you had a special romantic relationship with anyone? (2) Have you ever had sexual intercourse? (3) Not counting the people you have described as romantic relationships, have you ever had a sexual relationship with anyone?

Educational investment is measured with two time-varying variables: highest degree attained and school enrollment status at each age. Respondents reported the type and date of the highest degree received and whether they were still attending school at Wave 3 . The dates of degree completion (e.g., high school or college degree) were matched with the Wave 3 age and the century month of each birthday to determine the highest degree attained at the beginning of each age retrospectively. School enrollment status is a dichotomous variable indicating whether a respondent is currently enrolled or not.

\section{Missing Data and Complex Survey Design}

Missing data were handled with the multiple imputation procedure (Proc MI) in SAS. Five imputed datasets were generated using the Proc MI procedure. Multiple imputation (Rubin, 2004) is a procedure that utilizes the Monte Carlo technique to replace missing values with several simulated versions. Each of the simulated complete datasets is analyzed by standard methods, and the results are combined to produce estimates and confidence intervals that incorporate missing data uncertainty (http://www.stat.psu.edu/\%7Ejls/mifaq.html-ref). In the analyses that follow, both descriptive statistics and the output for the event history models are the combined outputs from five imputed datasets using Rubin's rules. The complex survey design of Add Health was dealt with by using the SAS-callable SUDAAN program. Appropriate longitudinal sampling weights were applied to the statistical models. In addition, clustering and stratifying variables were taken into account to adjust the standard errors.

\section{Analysis Plan}

Descriptive statistics are presented separately for White and Asian respondents. Then, discrete-time event history analyses are presented to examine the roles of sociodemographic variables, family socialization, adolescent values and attitudes, adolescents' sexual and romantic relationship experiences, and educational investments in transitions to first marriage and first cohabitation. Logistic regression was used to estimate a series of nested discrete-time event history models. Interactions between race (Asian versus White) and each of the six family socialization and adolescent values/attitudes variables were examined to determine whether family influences have a stronger impact on Asians than on Whites. Finally, we utilize the Clogg test (Clogg, Petkova, \& Haritou, 1995) to determine whether coefficient changes across models are statistically significant.

\section{Results \\ Descriptive Statistics}

Although generational status overlaps with race and there are too few cases in specific Asian subgroups to make subgroup distinctions in our multivariate analyses, descriptive information is provided for Asian Americans in different generations and in three subgroups. Table 1 presents the weighted means and percentage distributions for all variables. The first panel shows that Asian Americans are significantly less likely to form a first union, especially a cohabitating union, than Whites. Fully $50 \%$ of Whites had entered a cohabiting union by Wave 3, compared to only $30 \%$ of Asian Americans. The comparable figures for marriage are $29 \%$ for Whites and $19 \%$ for Asian Americans. In the middle three columns, no generational differences is observed for likelihood of marriage among Asian Americans. First- and second-generation Asian Americans are less likely than the third-generation to have cohabited by Wave 3. The last three columns show that very few East Asians marry in 
young adulthood (9\%), whereas Other Asians marry at a rate comparable to that of Whites (29\%). In addition, all Asian subgroups are less likely to cohabit than Whites.

In the second panel, Asian American adolescents have a very different sociodemographic profile than Whites. A higher percentage of Asian American adolescents had mothers who did not complete high school (23\% versus $11 \%$ ) or who completed college (41\% versus $26 \%$ ) than White adolescents. The former pattern is particularly true for first-generation Asian youth and for Other Asian youth. In addition, Asian American teens are more likely to come from two-biological-parent families (72\% versus $60 \%$ ) and less likely to live in stepfamilies (10\% versus 16\%) or single-parent families (13\% versus 19\%) than Whites. This is especially true for Asian youth with ethnic origins in East Asia and the Other Asian region. The diversity across subgroups is due to the two different streams of immigration from Asia: voluntary and involuntary (Zhou, 2007). Voluntary Asian immigrants are much more likely to have high socioeconomic status than involuntary immigrants who come to the United States because of refugee status or other forms of persecution.

The parents of Asian American adolescents have higher aspirations for their children's postsecondary education and higher levels of religiosity than do the parents of White adolescents. Parental aspirations for children's college attendance are higher among firstand second-generation Asian youth and for all subgroups. Group differences in family values are also reflected in the fact that the Asian American youth perceive greater negative social consequences of sex than do White youth. This pattern is also observed among firstgeneration Asian youth and those of East Asian and Filipino background. In addition, a much lower percentage of Asian American youth had been involved in romantic or sexual relationships by Wave 1 than White youth. For example, 53\% of Whites report having had a sexual experience compared to $32 \%$ of Asians. When broken down by generation, the lower likelihood is particularly strong among first-generation youth. There are more variations in romantic and sexual behaviors by Asian subgroup.

Finally, the panel for time-varying educational investments demonstrates that Asian American adolescents are less likely to have no degree and more likely to be currently enrolled in school. This pattern was observed for both the transition to first marriage and the first cohabitation data files.

\section{Transition to First Marriage}

Table 2 presents discrete-time event history models of the transition to first marriage. The first column shows odds ratios that summarize the bivariate relationships between each predictor and the transition to marriage. Model 1 includes race, age, and gender, and shows that Asian Americans are much less likely to marry in early adulthood $(\mathrm{OR}=0.62, \mathrm{p}<.05)$ than Whites. This difference persists even after sociodemographic controls are entered in Model $2(\mathrm{OR}=0.65, \mathrm{p}<.05)$. The other sets of variables (entered in Models 3 through 6 ) further reduce the difference between Asians and Whites and generally influence marriage in the expected direction. In Model 3, which adds parental values and attitudes, parental disapproval of adolescent sex is related negatively to early marriage, while parental religiosity is related positively to early marriage. In Model 4, stronger motivation to have sex in adolescence is associated with a lower likelihood of entering marriage in early adulthood. This may be due to lower levels of conservatism among those who are strongly motivated to engage in adolescent sex. However, those who actually have sex or a romantic relationship in adolescence are much more likely to marry early than those who do not (as shown in Model 5). This last set of variables is by far the most critical in closing the racial gap in odds of marriage, based on the Clogg test for the significance of changes in coefficients across models (absolute $Z>=1.96$ ). Finally, being in school decreases the risk 
of early marriage, while completing high school without further education increases the likelihood of marriage.

Interactions between race and each of the measures of family and adolescent values were tested to determine whether values have a stronger influence on the marriage behavior of Asians than Whites. Three interaction terms are significant (Models 7, 8, and 9): Asian by parental disapproval of sex $(\mathrm{OR}=0.78, \mathrm{p}<.05)$, Asian by high perceived social consequences of sex $(\mathrm{OR}=0.86, \mathrm{p}<.05)$, and Asian by consider having kids as an unmarried person $(\mathrm{OR}=2.35, \mathrm{p}<.01)$. All other things equal, parental disapproval of sex during adolescence and adolescents' own perceptions of the social consequences of sex have stronger dampening effects on early marriage among Asians than Whites. These interactions provide some support for the hypothesis that Asian youth are more likely than White youth to consider their parents' perspective when making choices about forming marital unions. The third interaction term indicates that acceptance of having children as an unmarried person has a more positive influence on marriage among Asians than among Whites. Further analyses indicate that Asian American youth who consider having children out of wedlock acceptable are two times more likely than White youth to come from single-parent families, even though Asian youth in general are less likely to come from single-parent families. This unusual relationship may underlie the significant interaction between being Asian and considering non-marital childbirth in our models predicting marriage.

\section{Transition to First Cohabitation}

Table 3 focuses on entry into cohabitation. As shown in Model 1, Asian American youth are less likely to enter cohabitation in early adulthood than are White youth $(\mathrm{OR}=0.51, \mathrm{p}<.001)$, and this negative relationship is stronger than that observed for marriage in Model 1 of Table 2. The lower likelihood of cohabitation for Asian Americans persists across models.

Models 2 through 4 show that higher maternal education reduces the odds of forming a cohabiting union in early adulthood, but in Model 5 (which adds adolescent sexual and romantic relationship experience) maternal education is no longer significant. This pattern indicates that maternal education affects cohabitation in part through adolescents' intimate relationship experiences. The full model (Model 6) shows that those most likely to cohabit are individuals from stepfamilies, single-parent families or "other" families, those who indicated in adolescence that they would consider childbearing as an unmarried person, and those who had romantic and sexual relationships in adolescence. Cohabitation is less common among men and women who were raised by more religious parents and those who were still enrolled in school. According to the Clogg test for the significance of changes in coefficients across models, the Asian-White difference in the odds of cohabitation is reduced significantly by the inclusion of measures of family socialization and adolescent intimate relationship experience. It becomes nonsignificant once the measures of educational engagement are added. Finally, none of the six interaction terms was significant. Contrary to our expectations, family values do not seem to have a stronger influence on the likelihood of early cohabitation among Asian Americans than among Whites.

\section{Conclusions}

This study investigated the processes underlying the low rates of early union formation among Asian Americans relative to Whites. Five research hypotheses were proposed and tested. The first hypothesis was that parental values partially explain Asian-White differences in union formation. This hypothesis received support in models of cohabitation, but not in models of marriage. Perhaps the Asian-White marriage gap is driven by other aspect of family values not measured in this study, such as ideal age at marriage or preferred sequence of major transition in early adulthood (e.g., college completion, entry into 
workplace, and marriage, etc.). The Asian-White difference in cohabitation was significantly reduced when measures of family socialization were added to a model that included only sociodemographic controls. In particular, the lower cohabitation rate among Asian Americans can be explained by the fact that their parents are more religious. This resonates with prior research that shows parental values and preferences affect family behaviors of offspring (Axinn \& Thornton, 1993; Barber, 2000; Barber \& Axinn, 1998).

The second hypothesis was that differences between Asian American and White youth's values regarding sex partially account for Asian-White differences in the risk of early union formation. This hypothesis was not supported for either marriage or cohabitation. Hypothesis 3 proposed that parents' and adolescents' values have a stronger influence on union formation among Asian American youth than White youth. This hypothesis was supported for marriage but not cohabitation. Parental disapproval of sex and adolescents' perceptions of the social consequences of sex are more strongly associated with delayed marriage among Asian Americans than Whites, holding other characteristics constant. Further, Asian adolescents who are accepting of nonmarital childbearing are more likely than their White counterparts, all else equal, to enter marriage early. Together, the findings for the above three hypotheses are consistent with the idea that the expectations of others are more crucial in determining Asian American youth's marriage timing than White youth's marriage timing.

Hypothesis 4 received strong support because sexual and romantic relationship experience in adolescence partially explained the Asian-White difference in both marriage and cohabitation. The Asian-White difference went from marginally significant to nonsignificant for marriage and from an odds ratio of 0.61 to an odds ratio of 0.70 for cohabitation. Both coefficient changes were significant. Finally, Hypothesis 5 states that educational investments contribute to the relatively low odds of early union formation among Asian Americans compared to White Americans. This hypothesis was supported for cohabitation. The critical feature of education for union formation is remaining in school.

Asian American adolescents grow up learning traditional values that teach them to delay gratification from intimate dyadic relationships and to focus on achieving academically (Espiritu, 2001; Wolf, 1997; Zhou, 2007). These family influences are deeply internalized (Espiritu, 2001; Wolf, 1997) and are reflected in Asian American youth's lower motivation for and involvement in sexual/romantic relationships, which lengthens the time to first marriage. The models show that limited involvement in intimate relationships in late adolescence is a major factor underlying the Asian-White gap in early marriage. In addition, the impacts of parental disapproval of sex and perceived social consequences of sex on marriage are stronger for Asian Americans than Whites. Family value socialization, intimate relationship experiences, and educational engagement each have unique contributions in explaining Asian-White differentials in entry into first cohabitation.

This research shows that in addition to concrete behavioral indicators such as school attendance, employment status, and dating experience, future research on union formation among Asian Americans should pay attention to the impact of intergenerational transmission of values, beliefs, and attitudes to better understand and conceptualize family processes within this racial group. In particular, given that Asian parents put stricter constraints on daughters' than on sons' dating and social life (Espiritu, 2001) and that intergenerational influence on family behaviors can be gendered (Axinn \& Thornton, 1993), researchers should also investigate whether the impact of family values affect Asian male and female youth differently and the implications of it if there are indeed different processes involved. 
Finally, the results of this study should prompt researchers to think about the meaning of cohabitation and its influence on later family processes among Asian Americans. Asian Americans who enter a cohabiting union may be even much more non-traditional than Whites who cohabit. It is thus intriguing to consider the quality and stability of marriage among Asian American couples who cohabited premaritally. One might think that the positive relationship between premarital cohabitation and divorce risk might be more pronounced for Asian Americans because of the relative "unconventionality" of cohabitation in the Asian American community. This is an interesting question for future research.

There are several things that might have improved this study. First, there are no variables that measure parental attitudes toward dating, cohabitation, or marriage in the Add Health study. If these variables were available, they would be more direct measures of family influences on attitudes and behaviors regarding the ideal timing and sequence of union formation. In this study, we can only gauge family influences that relate to union formation by looking at parental aspirations for their adolescent's education, parental religiosity, and parents' attitudes about sex. Second, only unions formed by age 25 can be observed for this cohort of young adults born around the period from 1977 to 1980 . A complete understanding of the process of union formation among Asian Americans and Whites must await the $4^{\text {th }}$ Wave of Add Health data, which will reflect union experiences at later ages. Third, given the small sample of third-generation Asian American youth in this study, which leads to very few events of marriage and cohabitation, we could not investigate how generation status affects the influence of family socialization on union formation. It is likely that the influence of Asian values is weaker among the more acculturated third-generation Asian American youth, which may make them have first union patterns that are more similar to those of White Americans. Due to limitations in sample size and the number of events, we also could not investigate differences in union formation patterns of Asian subgroups.

To our knowledge, this is the first empirical study based on a national sample of a recent cohort of Asian American youth to examine the formation of both marital and cohabiting unions with a conceptual framework that incorporates multiple sets of predictors. The results reveal that Asian American young adults are less likely than White youth to enter marriage or cohabitation in early adulthood. The findings also highlight the importance of value socialization for Asian Americans' lower likelihood of early marriage, as well as sexual and romantic relationship experiences for the timing of cohabitation and marriage. Given the rapid growth of the Asian American population, we hope the current study will elicit further efforts to understand the family processes and behaviors of this growing minority group in the United States.

\section{Acknowledgments}

The authors would like to thank Alan Booth and Robert Schoen for helpful comments on an earlier version of this paper. Support for this research was provided by a grant from the NICHD, R01-HD045309. Support services were provided by the Population Research Institute, Pennsylvania State University, which has core support from the NICHD (R24-HD41025). This research uses data from Add Health, a program project designed by J. Richard Udry, Peter S. Bearman, and Kathleen Mullan Harris, and funded by a grant P01-HD31921 from the Eunice Kennedy Shriver National Institute of Child Health and Human Development, with cooperative funding from 17 other agencies. Special acknowledgment is due Ronald R. Rindfuss and Barbara Entwisle for assistance in the original design. Persons interested in obtaining data files from Add Health should contact Add Health, Carolina Population Center, 123 W. Franklin Street, Chapel Hill, NC 27516-2524 (addhealth@ unc.edu). No direct support was received from grant P01-HD31921 for this analysis.

\section{References}

Asakawa K, Csikszentmihalyi M. Feelings of Connectedness and Internalization of Values in Asian American Adolescents. Journal of Youth and Adolescence. 2000; 29:121-145. 
Axinn WG, Thornton A. Mothers, Children, and Cohabitation: The intergenerational effects of attitudes and behavior. American Sociological Review. 1993; 58:233-246.

Barber JS. Intergenerational influences on the entry into parenthood: Mothers' preferences for family and nonfamily behavior. Social Forces. 2000; 79:319-348.

Barringer, HR.; Takeuchi, DT.; Xenos, P. Education, Occupational Prestige, and Income of Asian Americans. In: Nakanishi, DT.; Nishida, TY., editors. The Asian American Educational Experience: A Source Book for Teachers and Students. Routledge; New York, NY: 1995.

Carver, K.; Joyner, K.; Udry, JR. National Estimates of Adolescent Romantic Relationships. In: Florsheim, P., editor. Adolescent Romantic Relations and Sexual Behavior: Theory, Research, and Practical Implications. Lawrence Erlbaum Associates, Inc.; Mahwah, NJ: 2003. p. 23-56.Publishers

Casper, LM.; Bianchi, SM. Continuity and Change in the American Family. Sage Publications Inc.; 2002.

Chan, CS. Asian American Adolescents: Issues in the expression of sexuality. In: Irvine, JM., editor. Sexual Cultures and the Construction of Adolescent Identities. Temple University Press; Philadelphia, PA: 1994. p. 89-99.

Cheng C. Familism the Foundation of Chinese Social Organization. Social Forces. 1944; 23:50-59.

Chris BH, Hahm M. Asian American Adolescents' First Sexual Intercourse: Gender and Acculturation Differences. Perspectives on Sexual and Reproductive Health. 2006; 38:28-36. [PubMed: 16554269]

Clogg CC, Petkova E, Haritou A. Statistical methods for comparing regression coefficients between models. American Journal of Sociology. 1995; 100:1261-1293.

Crissey SR. Race/ethnic Differences in the Marital Expectations of Adolescents: The role of romantic relationships. Journal of Marriage and Family. 2005; 67:697-709.

Edin, K.; Kefalas, M. Promises I Can Keep: Why Poor Women Put Motherhood Before Marriage. University of California Press; 2005.

Espiritu YL. "We Don't Sleep Around Like White Girls Do": Family, Culture, and Gender in Filipina American Lives. Signs: Journal of Women in Culture and Society. 2001; 26:415-440.

Glick JE, Ruf SD, White MJ, Goldscheider F. Educational Engagement and Early Family Formation. Social Forces. 2006; 84:1391-1415.

Harris?

Hango DW, Le Bourdais C. Early Union Formation in Canada: Links with Education. European Journal of Population. 2007; 23:339-368.

Hirschman C, Wong MG. The Extraordinary Educational Attainment of Asian-Americans: A Search for Historical Evidence and Explanations. Social Forces. 1986; 65:1-27.

Hogan DP, Kitagawa EM. The Impact of Social Status, Family Structure, and Neighborhood on the Fertility of Black Adolescents. The American Journal of Sociology. 1985; 90:825-855.

Jones GW. The" Flight from Marriage" in South-East and East Asia*. Journal of Comparative Family Studies. 2005; 36:93-120.

Jones GW. Delayed Marriage and Very Low Fertility in Pacific Asia. Population and Development Review. 2007; 33:453-478.

Manning WD, Smock PJ. Why Marry? Transitions to Marriage among Cohabitors. Demography. $1995 ; 32$

Manning WD, Longmore MA, Giordano PC. The Changing Institution of Marriage: Adolescents Expectations to Cohabit and to Marry. Journal of Marriage and Family. 2007; 69:559-575.

Mare, RD.; Winship, C. Socioeconomic Change and the Decline of Marriage for Blacks and Whites. In: Jencks, C.; Peterson, PE., editors. The Urban Underclass. The Brookings Institution Press; 1991.

Markus HR, Kitayama S. Culture and the self: Implications for cognition, emotion, and motivation. Psychological Review. 1991; 98:224-253.

McLanahan S, Bumpass L. Intergenerational Consequences of Family Disruption. The American Journal of Sociology. 1988; 94:130-152.

Nakanishi, DT.; Yamano Nishida, T. The Asian American Educational Experience. A Source Book for Teachers and Students. Routledge; New York, NY: 1995. 
Raley RK, Crissey S, Muller C. Of Sex and Romance: Late Adolescent Relationships and Young Adult Union Formation. Journal of Marriage and Family. 2007; 69:1210-1226. [PubMed: 20221420]

Regnerus MD. Linked Lives, Faith, and Behavior: Intergenerational religious influence on adolescent delinquency. Journal for the Scientific Study of Religion. 2003; 42:189-203.

Rubin, DB. Multiple Imputation for Nonresponse in Surveys. J. Wiley \& Sons; New York: 2004.

Schoen R, Landale NS, Daniels K, Cheng Y. Social Class Differences in Early Family Behavior. Journal of Marriage and Family. 2009; 71:384-395.

Staples R, Mirande A. Racial and Cultural Variations among American Families: A Decennial Review of the Literature on Minority Families. Journal of Marriage and Family. 1980; 42:887-903.

Thornton A, Axinn WG, Hill DH. Reciprocal Effects of Religiosity, Cohabitation, and Marriage. The American Journal of Sociology. 1992; 98:628-651.

Thornton A, Axinn WG, Teachman JD. The Influence of School Enrollment and Accumulation on Cohabitation and Marriage in Early Adulthood. American Sociological Review. 1995; 60:762774.

Troyer L, Wesley Younts C. Whose Expectations Matter? The Relative Power of First- and SecondOrder Expectations in Determining Social Influence. American Journal of Sociology. 1997; 103:692-732.

Williams L, Kabamalan M, Ogena N. Cohabitation in the Philippines: Attitudes and Behaviors Among Young Women and Men. Journal of Marriage and Family. 2007; 69:1244-1256.

Wolf DL. Family Secrets: Transnational struggles among children of Filipino immigrants. Sociological Perspectives. 1997; 40:457-482.

Zhou, M. Divergent Origins and Destinies: Children of Asian Immigrants. In: Paik, SJ.; Walberg, HJ., editors. Narrowing the Achievement Gap: Strategies for educating Latino, Black, and Asian students. Springer; New York, NY: 2007. p. 109-128. 


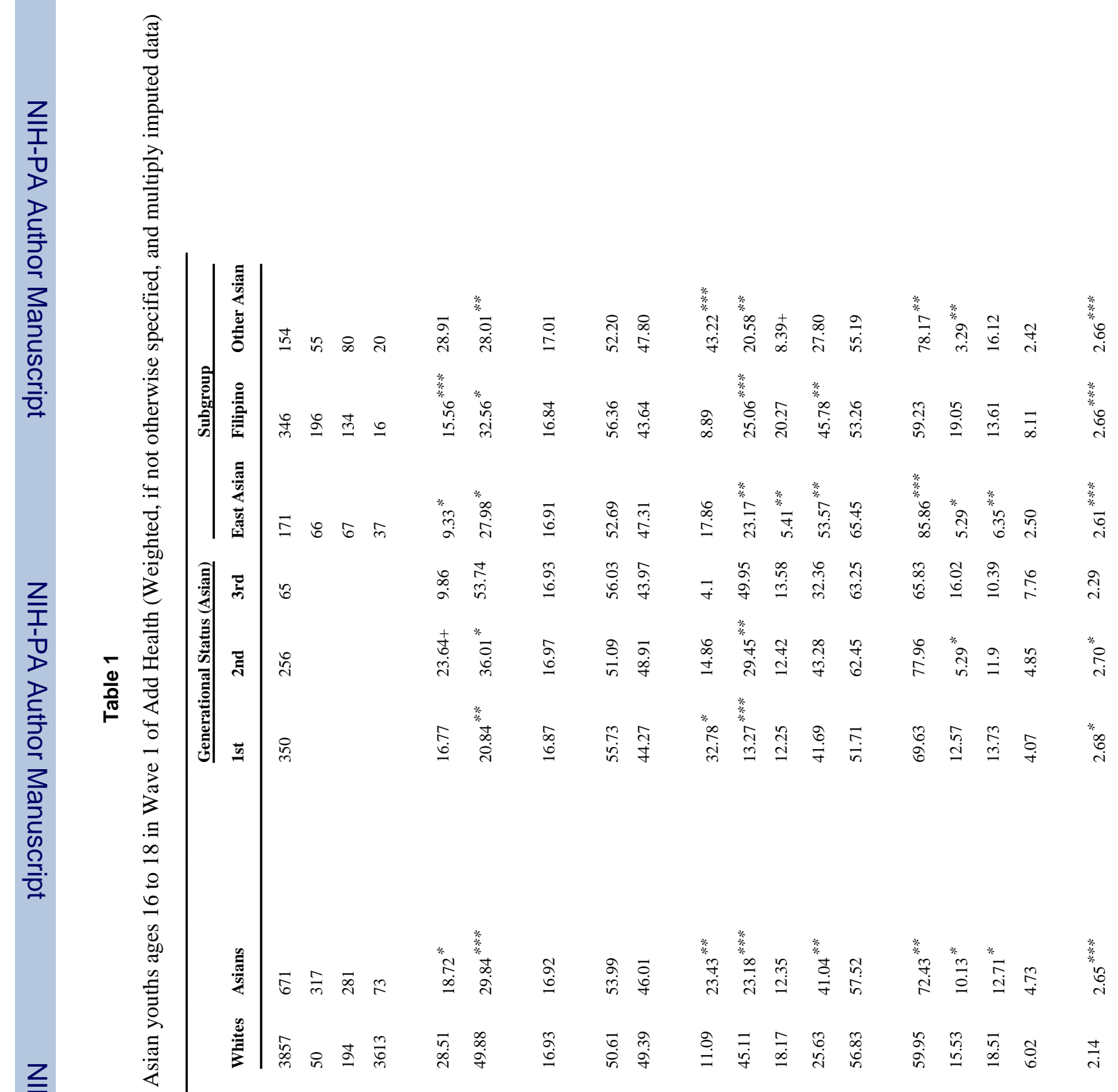




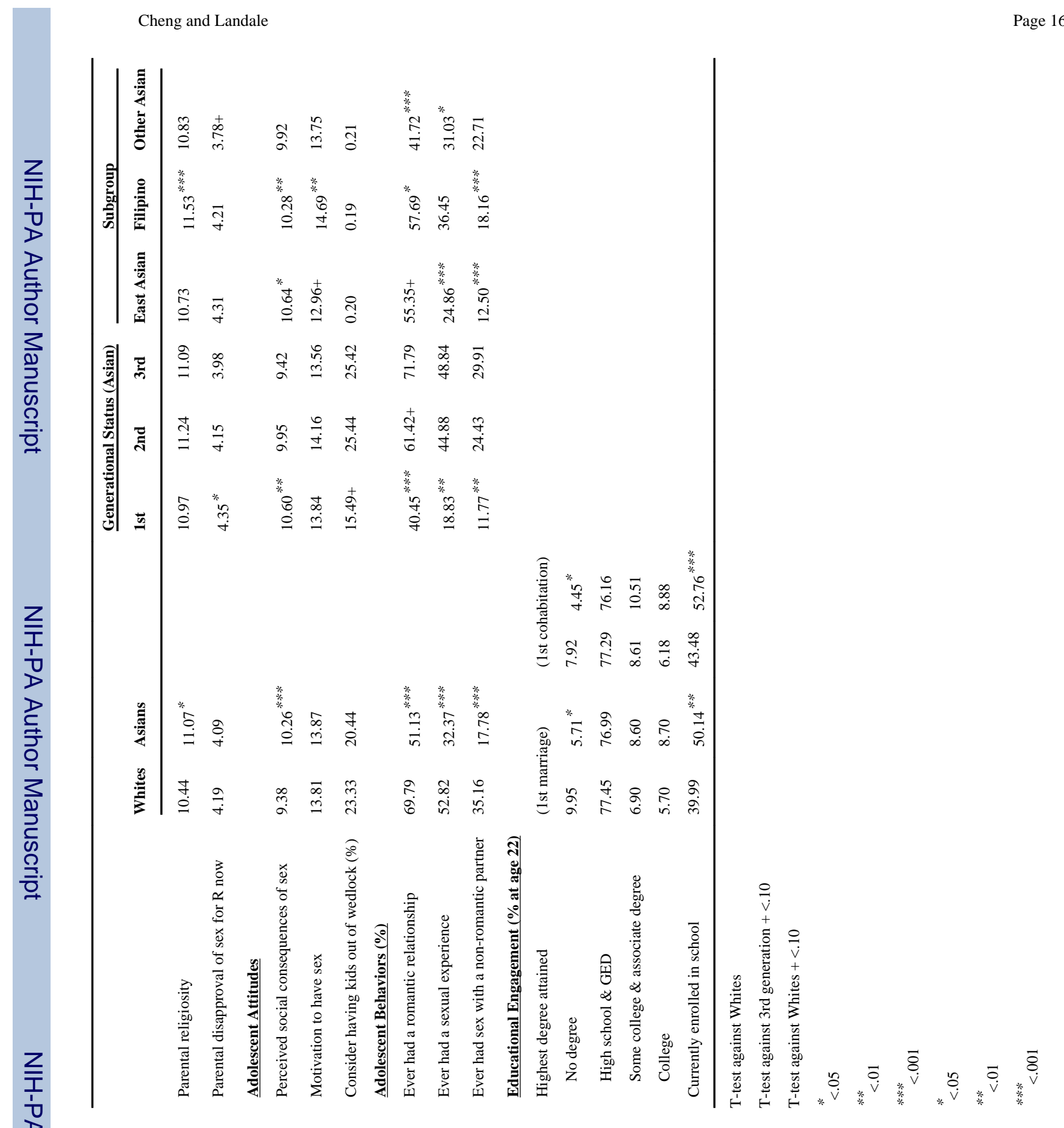

J Fam Issues. Author manuscript; available in PMC 2012 June 21. 


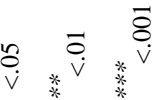




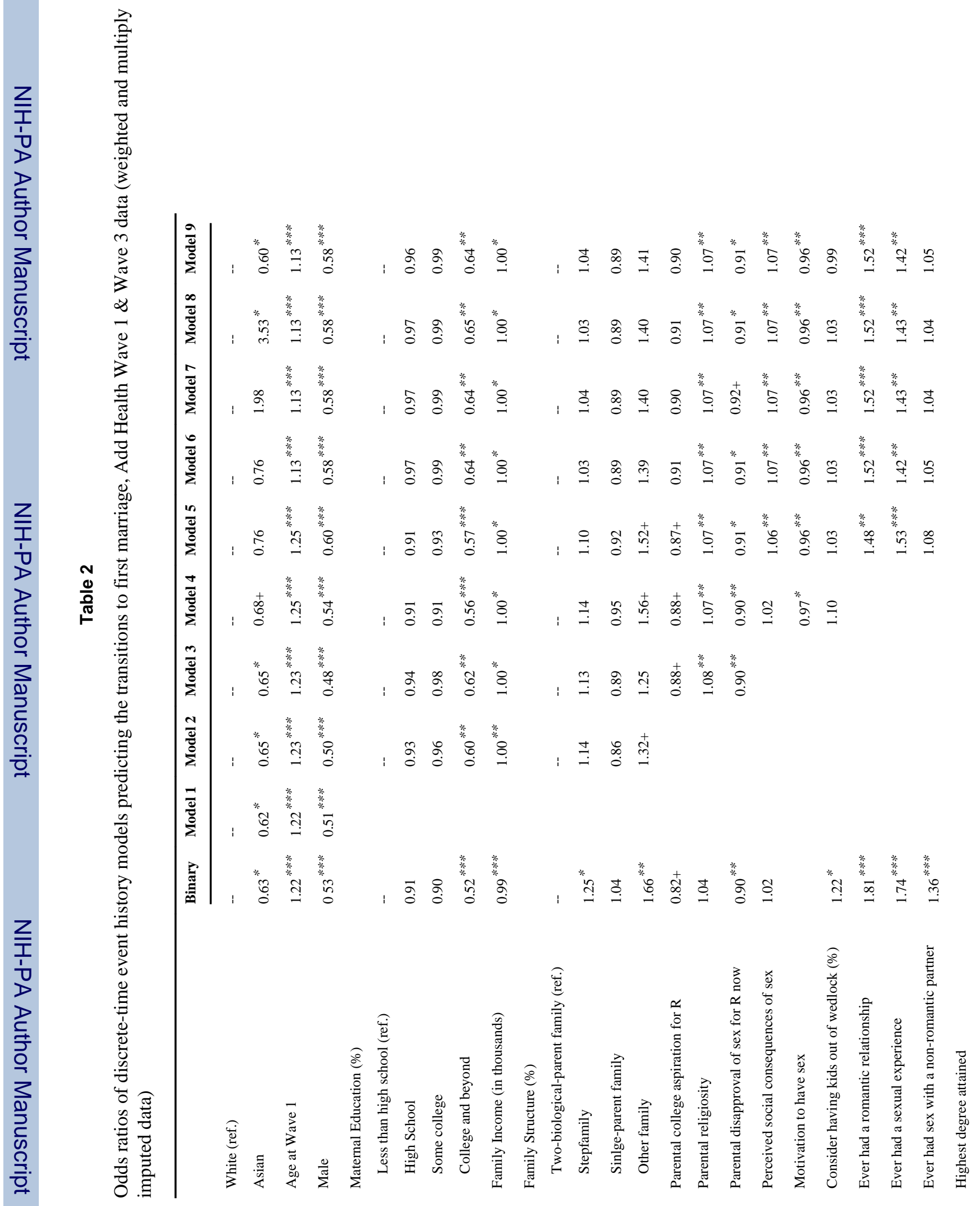




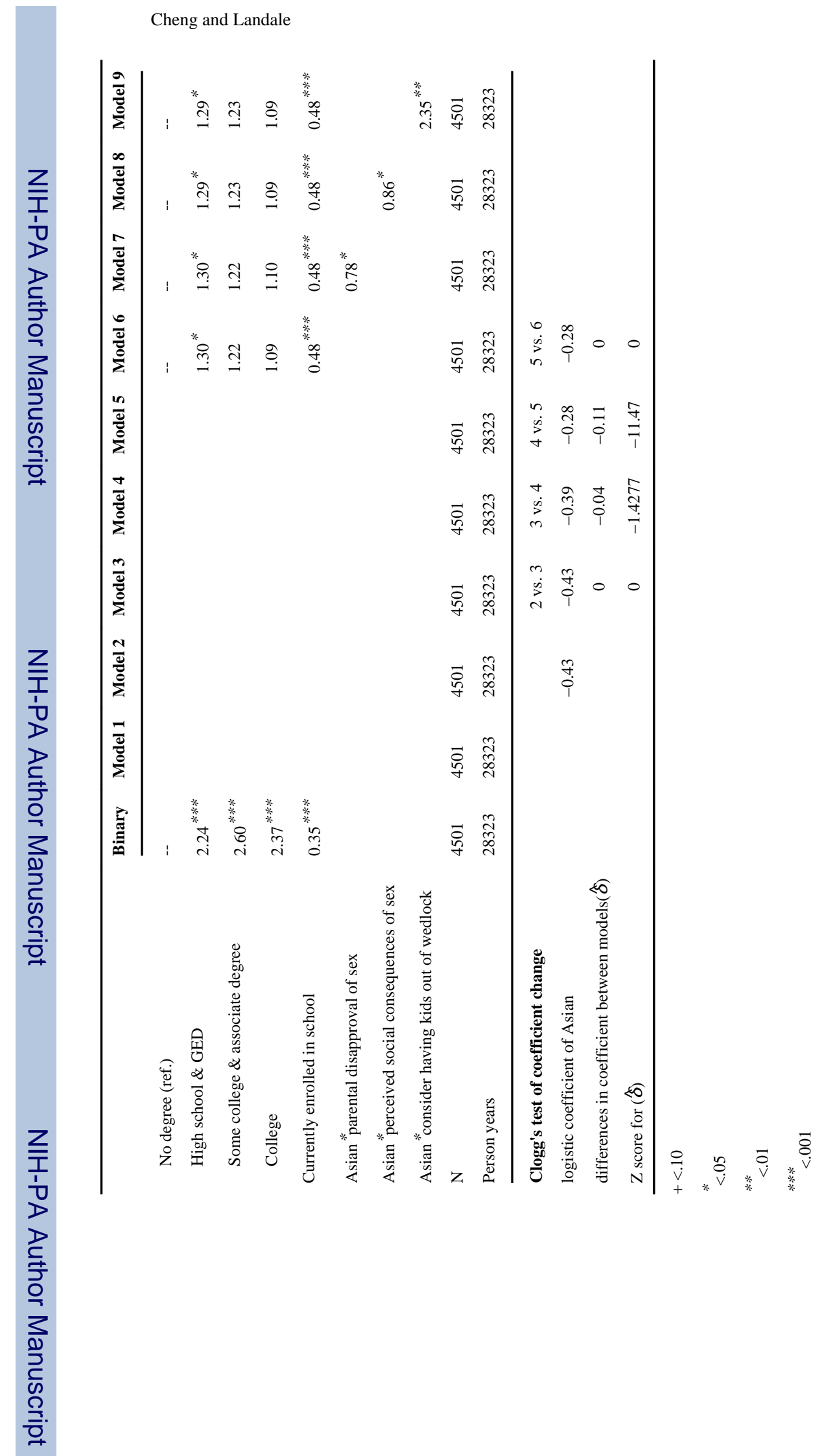

J Fam Issues. Author manuscript; available in PMC 2012 June 21. 


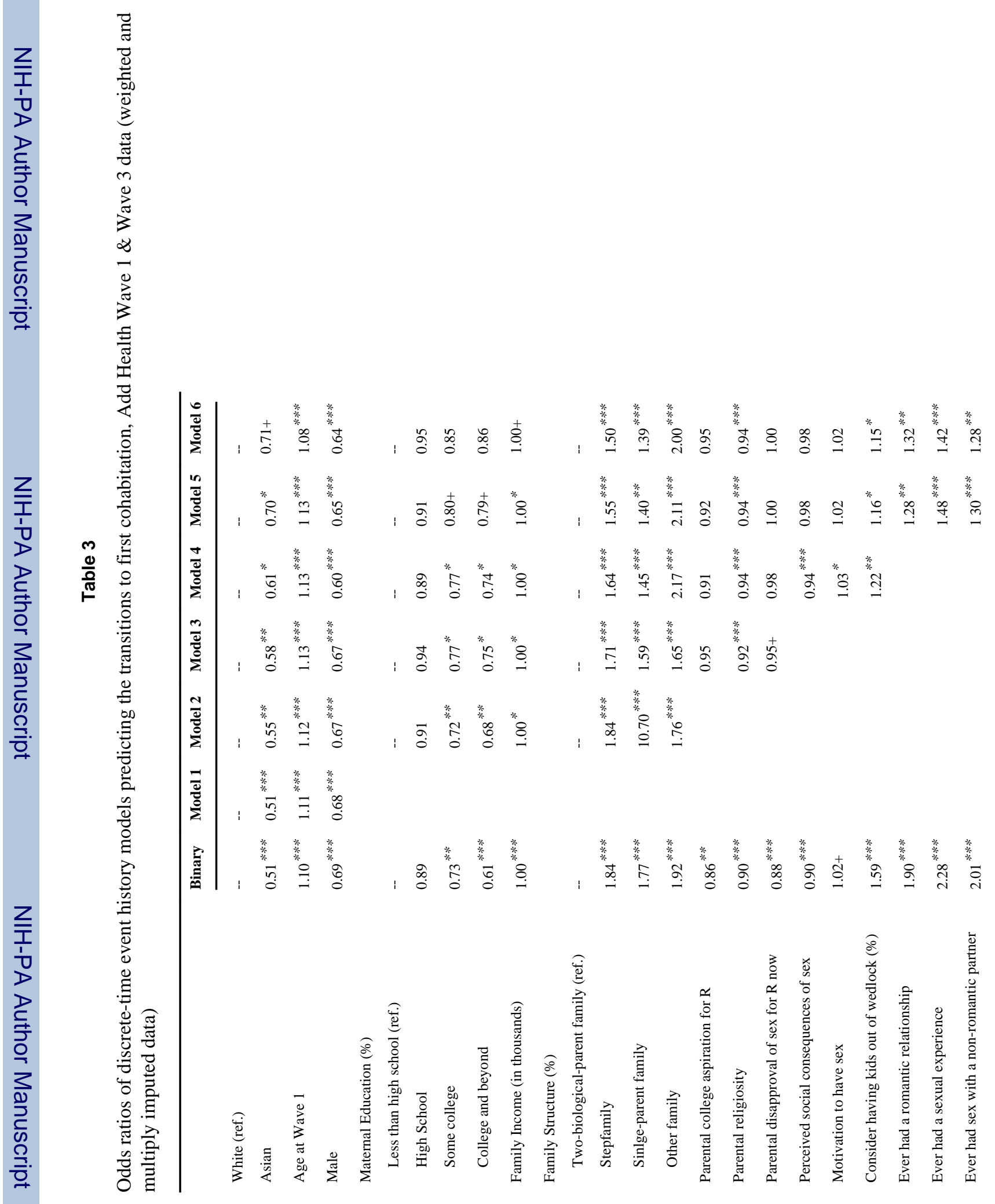




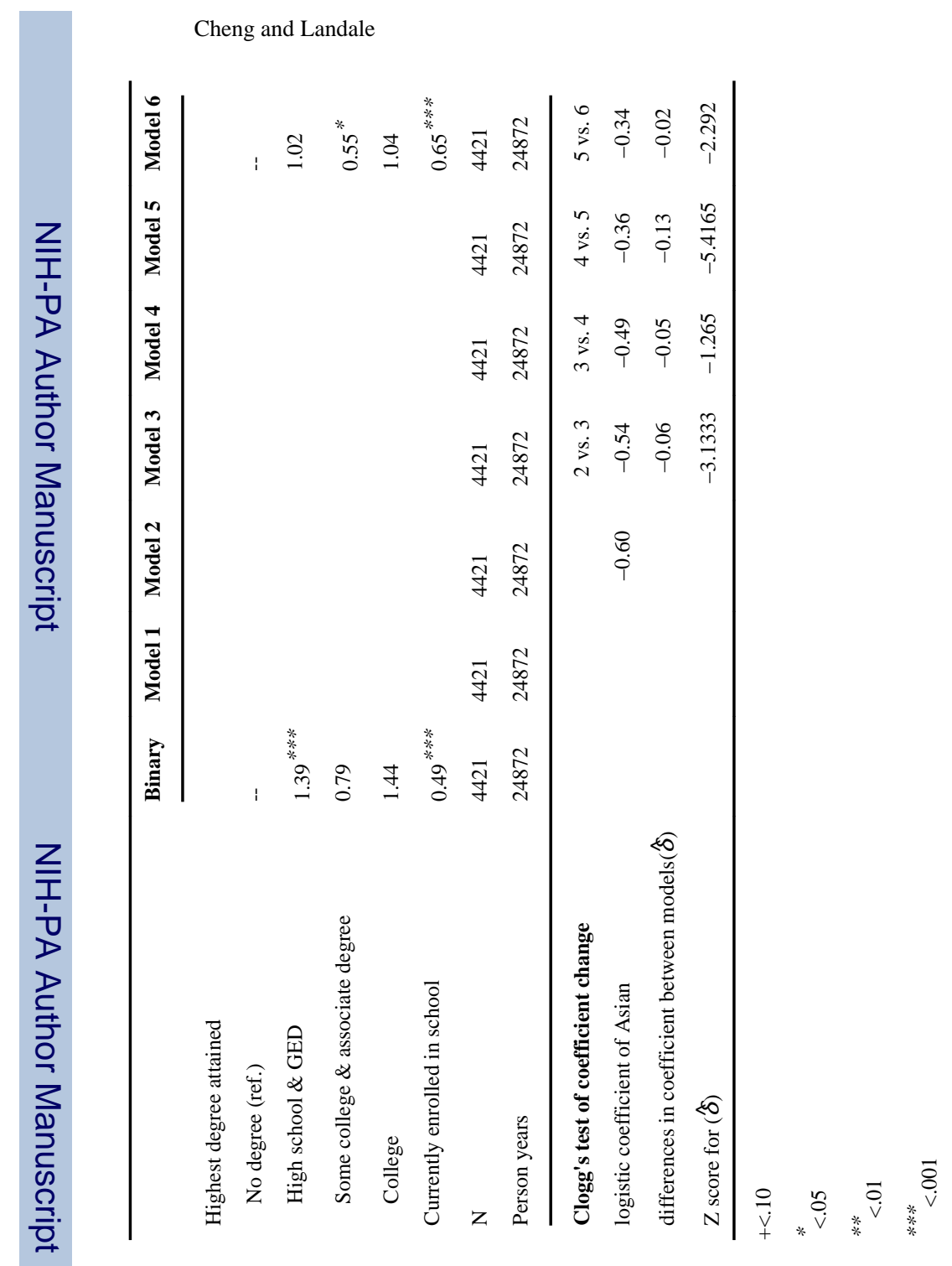

Page 21

J Fam Issues. Author manuscript; available in PMC 2012 June 21. 